\title{
Early Osteoporosis Risks and Associated Factors among Caregivers Working in Disability Institutions: IOF One-Minute Osteoporosis Risk Check
}

\author{
Lan-Ping Lin ${ }^{1}$, Wei-Ju Lai ${ }^{2}$, Shang-Wei Hsu ${ }^{3}$ and Jin-Ding Lin ${ }^{4, *}$ \\ 1 Department of Senior Citizen Care and Welfare, Ching Kuo Institute of Management and Health, \\ Keelung 203, Taiwan; lanping518@gmail.com \\ 2 School of Public Health, National Defense Medical Center, Taipei 144, Taiwan; weiju.lai1990@gmail.com \\ 3 Department of Healthcare Administration, Asia University, Taichung 354, Taiwan; shangweihsu@gmail.com \\ 4 Institute of Long-Term Care, Mackay Medical College, New Taipei City 252, Taiwan \\ * Correspondence: jack.lin4691@mmc.edu.tw
}

Received: 20 April 2020; Accepted: 8 May 2020; Published: 10 May 2020

\begin{abstract}
This study employed the International Osteoporosis Foundation's One-Minute Osteoporosis Risk Test to examine factors related to the osteoporosis risk of institutional caregivers. In this cross-sectional study, a self-developed structured questionnaire comprising the One-Minute Osteoporosis Risk Test was used to obtain data on the caregivers' demographic data, health habits, working style, and osteoporosis risk. Seven disability welfare institutions were selected as research sites, and 465 copies of questionnaires were distributed to the institutions' employees, with 455 valid responses collected for a valid return rate of $98 \%$. SPSS for Windows (Version 20.0) was used to analyze questionnaire data; descriptive-statistical frequency, a $\chi^{2}$ test, and logistic regression were used to determine the correlation between demographic data, health habits, working style, and osteoporosis risk. The results revealed that primary risk factors include $<30 \mathrm{~min}$ of daily exercise (38\%), lack of dairy product or calcium tablet intake $(28 \%)$, and $<10 \mathrm{~min}$ of daily outdoor activity or not taking vitamin D supplements (29.9\%). In total, $395(86.8 \%)$ of the respondents scored less than 5 in the osteoporosis risk test; the remaining $60(13.2 \%)$ scored 5 or higher, revealing a high risk of early osteoporosis. An independent variable analysis revealed that the risk factors of early osteoporosis include age, education level, having undergone bone density tests, prior disease diagnosis, long-term medication use, physical fitness, dietary habits, and average time of exposure to sunlight. In the multivariate analysis, poor physical fitness (odds ratio $[\mathrm{OR}]=2.18,95 \%$ confidence interval $[\mathrm{CI}]$ : $1.12-4.27, p=0.023)$ and average daily time of exposure to sunlight (OR $=0.24,95 \%$ CI: $0.59-2.59$, $p<0.001)$ were significantly correlated with osteoporosis risk. In other words, respondents with poor physical fitness were 2.18 times as likely to have osteoporosis as those with good physical fitness, and those exposed to sunlight for $30 \mathrm{~min}$ or longer every day were 0.24 times as likely to have osteoporosis as those exposed to sunlight for less than 30 min every day. Accordingly, institutions must encourage employees to spend more time in the sun every day and improve their physical fitness through exercise.
\end{abstract}

Keywords: osteoporosis; bone fracture; One-Minute Osteoporosis Risk Test; health promotion; exercise

\section{Introduction}

Osteoporosis-induced bone fracture is a serious public health problem that can result in serious diseases or early death [1]. Osteoporosis is a silent disease: it is difficult to notice at an early clinical stage, and only after the occurrence of spinal or hip fracture can a severe loss in bone density be detected [2]. Factors leading to bone fracture are classified into direct (congenital) and indirect (acquired) 
factors. Direct factors include age, body type, heredity, hormones, sex, and ethnicity. People with slimmer bodies or who are older are more vulnerable to osteoporosis. Hereditary factors, such as family medical history, are also critical determinants of osteoporosis risk. Generally, women are 6-8 times as vulnerable to osteoporosis as men are; for women, bone density declines rapidly after menopause or decreased gonad function. Indirect factors primarily comprise environmental factors and health habits, such as smoking, excessive alcohol consumption, excessive caffeine consumption, lack of exercise, insufficient exposure to sunlight, insufficient calcium intake, insufficient or excessive protein intake, and long-term medication use [2-6].

A study in Singapore reported that only $58 \%$ of women aged 45 years or older had learned about osteoporosis, and that $69.5 \%$ were unaware that family medical history constitutes a critical risk factor [7]. A study in Taiwan reported that $15 \%$ of female urban residents were unaware of the threat of osteoporosis, and $15.5 \%$ did not consider it a serious disease [8]. According to an osteoporosis awareness survey of middle-aged men by Hou et al. [9], 35\% of the respondents thought that osteoporosis is only concerning for women with menopause, and $40 \%$ thought that osteoporosis is irrelevant to their health; furthermore, as for osteoporosis-induced fracture, $81 \%$ did not believe that osteoporosis can lead to death, and $91 \%$ underestimated the disease's fatality rate. Knowledge of osteoporosis must therefore be improved in the general public.

According to a survey by Chen et al. [10] of public health nurses responsible for public health education, $49.0 \%$ of respondents falsely considered aging-related declines in body height to be normal; $46.8 \%$ falsely considered osteoporosis to be easy to treat and diagnose, with no special attention required; and only $47.5 \%$ correctly identified the tools for diagnosing the disease. Because osteoporosis occurs silently and slowly, it is difficult to detect and treat at its early stage if medical personnel do not take the initiative to inquire about and examine the disease. In an investigation by Chang et al. [11] on how much doctors knew about osteoporosis prevention, although $88.8 \%$ of the respondents had diagnosed osteoporosis in patients, only $53.3 \%$ had continued to diagnose new cases of the disease every week. This indicates an insufficient awareness of osteoporosis among these doctors. Furthermore, only $51.3 \%$ of the respondents would actively discuss osteoporosis-related topics with others. Therefore, knowledge of osteoporosis must be improved among medical personnel.

In particular, caregivers in institutional workplaces are particularly vulnerable to bone and muscle diseases over the long term. This is because of their hermetic work environment, insufficient exposure to sunlight, and laborious work in taking care of patients. Moreover, most of these caregivers are at middle age or older, making them highly vulnerable to osteoporosis. Therefore, using the One-Minute Osteoporosis Risk Test, this study investigated risk factors for osteoporosis for caregivers in institutions caring for persons with disabilities.

\section{Method}

This cross-sectional study analyzed data from the Statistics on Welfare Institutions and Workers for the Disabled in 2015 covering the 271 disability institutions in Taiwan, which together employ 9449 caregivers [12]. This study excluded institutions in Fujian Province (offshore islands), analyzing data for the remaining 9400 caregivers as the study population. The caregivers include administrators, social workers, nursing personnel, instructors, life attendants, and trainers. According to the sample size calculator by Raosof, Inc. [13] (for a 95\% confidence interval [CI] and 5\% sampling error), a representative sample must have at least 370 people.

Data on osteoporosis risk factors and osteoporosis knowledge were collected for analysis through a structured questionnaire, which passed reliability and validity tests. Seven disability welfare institutions mainly caring for people with intellectual disabilities or related multiple disabilities, were selected as research sites. Of the 465 copies of the questionnaire distributed to the caregivers, 455 valid responses were returned for a valid return rate of $98 \%$.

Specifically, the questionnaire asked caregivers about study informed consent firstly, and then their demographic data, health habits, and working style. Risk of osteoporosis was measured using the 
Chinese edition of the One-Minute Osteoporosis Risk Test. This Chinese version was translated and edited by the Taiwanese Osteoporosis Association, according to the original version provided by the International Osteoporosis Foundation. The risk test evaluates several crucial risk factors in 19 items, which together have a total score of 19. A higher score indicates having more osteoporosis risk factors, and those with a high score must visit a specialist or have their bone density measured in a hospital. Specifically, according to research conducted outside of Taiwan, a score of 5 and 6.5 indicate a $70 \%$ and $100 \%$ risk of having osteoporosis, respectively; the osteoporosis risk test thus aids the detection of early-stage osteoporosis [14].

Questionnaire responses were coded in Microsoft Excel 2010 and analyzed in SPSS for Windows (Version 20.0). Descriptive-statistical frequency, a $\chi^{2}$ test, and logistic regression analysis were used to analyze the correlation between demographic variables, health habits, working style, and osteoporosis risk.

\section{Results}

The demographic characteristics of the respondents revealed that female caregivers accounted for $83.7 \%$, and male for $16.3 \%$. The average age of respondents was $43.5 \pm 11.5$ years old (range $=20-76$ years), with more than fifty percent possessing college and higher degrees. The respondents reported that $32.5 \%$ had chronic disease diagnosis and $22.9 \%$ accepted long-term medication currently. With regard to BMI among the respondents, $32.5 \%$ were obese (BMI: $\geq 27), 28.9 \%$ were overweight (BMI: 24-26.9), 47.1\% were normal (BMI: 18.5-23.9) and 3.5\% were underweight (BMI: <18.5).

Table 1 lists respondent data, segmented by osteoporosis risk; 395 (86.8\%) and 60 (13.2\%) of respondents scored $<5$ and $\geq 5$, respectively. Tables 2 and 3 present the distribution for nonmodifiable osteoporosis risk factors. As noted in Table 3, the primary lifestyle-associated risk factors were exercising for less than 30 min daily ( $38 \%$ ), insufficient dairy product or calcium tablet intake (28\%), and engaging in outdoor activities for less than 10 min daily or not taking vitamin D supplements (29.9\%).

In the univariate analysis between demographic data and osteoporosis risk, age $(p<0.002)$, education level $(p<0.001)$, disease diagnosis $(p<0.001)$, and long-term medication $(p<0.001)$ were significantly correlated with osteoporosis risks. This means that people who are prone to experiencing osteoporosis are aged 50 years or older, have low education levels, have diagnoses of other diseases, and have undergone long-term medication. Sex and body mass index were not significantly correlated with osteoporosis risk (Table 4). As for health habits, osteoporosis risk was significantly and positively correlated with having undergone bone density tests $(p=0.013)$ as well as physical fitness $(p<0.001)$, dietary habits $(p=0.048)$, and average time of exposure to sunlight $(p<0.001)$. Regular exercise and an individual's health condition were not significantly correlated with osteoporosis risk (Table 5). As for working style, osteoporosis risk was not significantly correlated with job title $(p=0.219)$, number of days at work $(p=0.632)$, number of hours at work $(p=0.395)$, shift work $(p=0.066)$, and work pattern $(p=0.196)$, as detailed in Table 6.

After the univariate analysis, logistic regression analysis was then conducted for the eight variables that were significantly correlated with osteoporosis risks, which were age, education level, prior disease diagnosis, having undergone bone density tests, long-term medication use, physical fitness, dietary habits, and average daily time of exposure to sunlight. The results are presented in Table 7. Model 1 tested whether the demographic factors predict osteoporosis risks, and its regression results revealed that respondents aged 50 years or older (odds ratio $[\mathrm{OR}]=5.52,95 \% \mathrm{CI}=1.17-25.93, p=0.03$ ) were 5.52 times as likely to experience osteoporosis as those aged 18-29 years. After physical fitness, dietary habits, and average daily time of exposure to sunlight were added into Model 2, age exhibited no significant correlation with osteoporosis risks. The results for Model 2 also indicated that physical fitness (OR $=2.18,95 \% \mathrm{CI}=1.12-4.27, p=0.023)$ and average time of exposure to sunlight $(\mathrm{OR}=0.24$, $95 \%$ CI $=0.59-2.59, p<0.001$ ) were significantly correlated with osteoporosis risk. This means that respondents with poor physical fitness were 2.18 times as likely to experience osteoporosis as those 
with good physical fitness, and that those who have an average daily time of exposure to sunlight for $30 \mathrm{~min}$ or longer were 0.24 times as likely to experience osteoporosis as those who had an average of less than $30 \mathrm{~min}$ of sunlight exposure every day.

Table 1. Osteoporosis risk groups *.

\begin{tabular}{cll}
\hline Risk Groups $^{* *}$ & $\mathbf{n}$ & \% \\
\hline$<5$ & 395 & 86.8 \\
$\geqq 5$ & 60 & 13.2
\end{tabular}

* Range: 0-16 for men; 0-18 for women. ${ }^{* *}$ A score of $\geq 5$ in the One-Minute Osteoporosis Risk Test indicates a high risk of osteoporosis; a "yes" response to an item does not mean that the respondent has osteoporosis but that the respondent exhibits the corresponding risk factor, and thus has a greater risk of osteoporosis.

Table 2. International Foundation for Osteoporosis (IOF One-Minute Osteoporosis Risk Test of caregivers $(n=455)$.

\begin{tabular}{|c|c|c|}
\hline Non-Modifiable Risk Factors * & $\mathbf{n}$ & $\%$ \\
\hline \multicolumn{3}{|c|}{$\begin{array}{l}\text { 1. Have either of your parents been diagnosed with osteoporosis or broken a bone after a minor } \\
\text { fall (a fall from standing height or less)? }\end{array}$} \\
\hline Yes & 58 & 12.7 \\
\hline No & 397 & 87.3 \\
\hline \multicolumn{3}{|l|}{ 2. Did either of your parents have a stooped back (dowager's hump)? } \\
\hline Yes & 50 & 11.0 \\
\hline No & 405 & 89.0 \\
\hline \multicolumn{3}{|l|}{ 3. Are you 40 years old or older? } \\
\hline Yes & 270 & 59.3 \\
\hline No & 185 & 40.7 \\
\hline \multicolumn{3}{|l|}{ 4. Have you ever broken a bone after a minor fall, as an adult? } \\
\hline Yes & 38 & 8.4 \\
\hline No & 417 & 91.6 \\
\hline \multicolumn{3}{|c|}{$\begin{array}{l}\text { 5. Do you fall frequently (more than once in the last year) or do you have a fear of falling because } \\
\text { you are frail? }\end{array}$} \\
\hline Yes & 25 & 5.5 \\
\hline No & 430 & 94.5 \\
\hline \multicolumn{3}{|c|}{ 6. After the age of 40 , have you lost more than $3 \mathrm{~cm}$ in height (just over 1 inch)? } \\
\hline Yes & 44 & 90.3 \\
\hline No & 411 & 9.7 \\
\hline \multicolumn{3}{|l|}{ 7. Are you underweight (is your Body Mass Index less than $19 \mathrm{~kg} / \mathrm{m}^{2}$ )? } \\
\hline Yes & 22 & 4.8 \\
\hline No & 433 & 95.2 \\
\hline \multicolumn{3}{|c|}{$\begin{array}{l}\text { 8. Have you ever taken corticosteroid tablets (cortisone, prednisone, etc.) for more than three } \\
\text { consecutive months? }\end{array}$} \\
\hline Yes & 21 & 4.6 \\
\hline No & 434 & 95.4 \\
\hline \multicolumn{3}{|l|}{ 9. Have you ever been diagnosed with rheumatoid arthritis? } \\
\hline Yes & 19 & 4.2 \\
\hline No & 436 & 95.8 \\
\hline \multicolumn{3}{|c|}{$\begin{array}{l}\text { 10. Have you been diagnosed with an over-active thyroid, overactive parathyroid glands, type } 1 \\
\text { diabetes or a nutritional/gastrointestinal disorder such as Crohn's or celiac disease? }\end{array}$} \\
\hline Yes & 19 & 4.2 \\
\hline No & 436 & 95.8 \\
\hline
\end{tabular}

* A score of $\geq 5$ in the One-Minute Osteoporosis Risk Test indicates a high risk of osteoporosis; a "yes" response to an item does not mean that the respondent has osteoporosis but that the respondent exhibits the corresponding risk factor, and thus has a greater risk of osteoporosis. 
Table 3. IOF One-Minute Osteoporosis Risk Test of caregivers (non-modifiable and lifestyle risk factors) $(\mathrm{n}=455)$.

\begin{tabular}{|c|c|c|}
\hline Non-Modifiable Risk Factors (cont.) & $\mathbf{n}$ & $\%$ \\
\hline \multicolumn{3}{|l|}{ For Women: } \\
\hline \multicolumn{3}{|l|}{ 11. For women over $45:$ Did your menopause occur before the age of 45 ? } \\
\hline Yes & 40 & 10.5 \\
\hline No & 341 & 89.5 \\
\hline \multicolumn{3}{|c|}{$\begin{array}{l}\text { 12. Have your periods ever stopped for twelve consecutive months or more (other than because of } \\
\text { pregnancy, menopause or hysterectomy)? }\end{array}$} \\
\hline Yes & 25 & 6.6 \\
\hline No & 356 & 93.4 \\
\hline \multirow{2}{*}{\multicolumn{3}{|c|}{$\begin{array}{l}\text { 13. Were your ovaries removed before age } 50 \text {, without you taking Hormone Replacement } \\
\text { Therapy? }\end{array}$}} \\
\hline & & \\
\hline Yes & 11 & 2.9 \\
\hline No & 370 & 97.1 \\
\hline \multicolumn{3}{|l|}{ For Men: } \\
\hline \multicolumn{3}{|c|}{$\begin{array}{l}\text { 14. Have you ever suffered from impotence, lack of libido or other symptoms related to low } \\
\text { testosterone levels? }\end{array}$} \\
\hline Yes & 3 & 4.1 \\
\hline No & 71 & 95.9 \\
\hline Lifestyle risk factors & $\mathbf{n}$ & $\%$ \\
\hline \multicolumn{3}{|c|}{ 15. Do you regularly drink alcohol in excess of safe drinking limits (more than two units a day)? } \\
\hline Yes & 11 & 2.4 \\
\hline No & 444 & 97.6 \\
\hline \multicolumn{3}{|l|}{ 16. Do you currently, or have you ever, smoked cigarettes? } \\
\hline Yes & 40 & 8.8 \\
\hline No & 415 & 91.2 \\
\hline \multicolumn{3}{|c|}{$\begin{array}{l}\text { 17. Is your daily level of physical activity less than } 30 \text { min per day (housework, gardening, } \\
\text { walking, running etc.)? }\end{array}$} \\
\hline Yes & 173 & 38.0 \\
\hline No & 282 & 62.0 \\
\hline \multicolumn{3}{|c|}{$\begin{array}{l}\text { 18. Do you avoid, or are you allergic to milk or dairy products, without taking any calcium } \\
\text { supplements? }\end{array}$} \\
\hline Yes & 131 & 28.8 \\
\hline No & 324 & 71.2 \\
\hline \multicolumn{3}{|c|}{$\begin{array}{l}\text { 19. Do you spend less than ten minutes per day outdoors (with part of your body exposed to } \\
\text { sunlight), without taking vitamin D supplements? }\end{array}$} \\
\hline Yes & 136 & 29.9 \\
\hline No & 319 & 70.1 \\
\hline
\end{tabular}

Table 4. Univariate analysis of demographic data and osteoporosis risk $(n=455)$.

\begin{tabular}{|c|c|c|c|c|}
\hline & $<5$ & $\geqq 5$ & & \\
\hline Variable & n (\%) & n (\%) & $x^{2}$ & $p$-Value \\
\hline Sex & & & 0.081 & 0.776 \\
\hline M & $65(87.8)$ & $9(12.2)$ & & \\
\hline $\mathrm{F}$ & $330(86.6)$ & $51(13.4)$ & & \\
\hline Age & & & 46.394 & $<0.001$ \\
\hline $18-29$ & $68(97.1)$ & $2(2.9)$ & & \\
\hline $30-39$ & $108(98.2)$ & $2(1.8)$ & & \\
\hline $40-49$ & $112(88.2)$ & $15(11.8)$ & & \\
\hline$\geq 50$ & $107(72.3)$ & $41(27.7)$ & & \\
\hline $\mathrm{BMI}^{*}(\mathrm{n}=454)$ & & & 1.352 & 0.717 \\
\hline Underweight & $15(93.8)$ & $1(6.3)$ & & \\
\hline Normal & $188(87.9)$ & $26(28.3)$ & & \\
\hline Overweight & $112(85.5)$ & $19(14.5)$ & & \\
\hline Obese & $79(84.9)$ & $14(15.1)$ & & \\
\hline
\end{tabular}


Table 4. Cont.

\begin{tabular}{lllll}
\hline & $<5$ & $\geqq 5$ & & \\
\hline Variable & $\mathbf{n ~ ( \% )}$ & $\mathbf{n ~ ( \% )}$ & $\chi^{2}$ & $p$-Value \\
\hline Education level & & & 35.782 & $<0.001$ \\
$\quad$ Elementary school & $16(61.5)$ & $10(38.5)$ & & \\
$\quad$ Junior high school & $26(81.3)$ & $6(18.8)$ & & \\
$\quad$ Senior high school & $128(80.0)$ & $32(20.0)$ & & \\
$\quad$ College & $214(94.7)$ & $12(5.3)$ & & \\
$\quad$ Graduate school or above & $11(100.0)$ & $0(0.0)$ & & \\
Disease diagnosis & & & 15.90 .3 & $<0.001$ \\
$\quad$ No & $280(91.2)$ & $27(8.8)$ & & \\
$\quad$ Yes & $115(77.7)$ & $33(22.3)$ & & \\
Long-term medication & $316(90.0)$ & $35(10.0)$ & & \\
$\quad$ No & $79(76.0)$ & $25(24.0)$ & & \\
$\quad$ Yes & & & & \\
\hline
\end{tabular}

Table 5. Univariate analysis of healthy lifestyle and osteoporosis risk $(n=455)$.

\begin{tabular}{|c|c|c|c|c|}
\hline & $<5$ & $\geq 5$ & & \\
\hline Variable & n (\%) & n $(\%)$ & $x^{2}$ & $p$-Value \\
\hline Health condition & & & 5.554 & 0.235 \\
\hline Very healthy & $38(90.5)$ & $4(9.5)$ & & \\
\hline Healthy & $159(86.9)$ & $24(13.1)$ & & \\
\hline Moderate & $169(86.2)$ & $27(13.8)$ & & \\
\hline Unhealthy & $27(90.0)$ & $3(10.0)$ & & \\
\hline Very unhealthy & $2(50.0)$ & $2(50.0)$ & & \\
\hline Bone density test & & & 6.127 & 0.013 \\
\hline Yes & $216(83.4)$ & 43 (16.6) & & \\
\hline No & $179(91.3)$ & $17(8.7)$ & & \\
\hline Physical fitness & & & 16.043 & $<0.001$ \\
\hline Satisfactory & $234(92.5)$ & $19(7.5)$ & & \\
\hline Unsatisfactory & $161(79.7)$ & $41(20.3)$ & & \\
\hline Dietary habits & & & 7.918 & 0.048 \\
\hline Very poor & $8(100.0)$ & $0(0.0)$ & & \\
\hline Poor & $120(82.2)$ & $26(17.8)$ & & \\
\hline Moderate & $242(87.7)$ & $34(12.3)$ & & \\
\hline Satisfactory & $25(100.0)$ & $0(0.0)$ & & \\
\hline Exercise & & & 0.073 & 0.786 \\
\hline No & $112(87.5)$ & $16(12.5)$ & & \\
\hline Yes & $283(86.5)$ & 44 (13.5) & & \\
\hline $\begin{array}{l}\text { Average daily time of } \\
\text { exposure to sunlight }\end{array}$ & & & 33.350 & $<0.001$ \\
\hline$<30 \mathrm{~min}$ & $119(74.4)$ & $41(25.6)$ & & \\
\hline$\geq 30 \mathrm{~min}$ & $276(93.6)$ & $19(6.4)$ & & \\
\hline
\end{tabular}

Table 6. Univariate analysis of working style and osteoporosis risk $(n=455)$.

\begin{tabular}{lllll}
\hline & $<5$ & $\geq 5$ & & \\
\hline Variable & $\mathbf{n ~ ( \% )}$ & $\mathbf{n ~ ( \% )}$ & $\chi^{2}$ & $p$-Value \\
\hline Job title & & & 1.508 & 0.219 \\
$\quad$ First-line & $272(85.5)$ & $46(14.5)$ & & \\
$\quad$ Non-first-line & $123(89.8)$ & $14(10.2)$ & & \\
\hline
\end{tabular}


Table 6. Cont.

\begin{tabular}{lllll}
\hline & $<5$ & $\geq 5$ & & \\
\hline Variable & $\mathbf{n ~ ( \% )}$ & $\mathbf{n ~ ( \% )}$ & $\chi^{2}$ & $p$-Value \\
\hline $\begin{array}{l}\text { Days at work } \\
\text { weekly }\end{array}$ & & & 0.229 & 0.632 \\
$\quad \leq 5$ days & $269(87.3)$ & $39(12.7)$ & & \\
$\quad>5$ days & $126(85.7)$ & $21(14.3)$ & & \\
$\begin{array}{l}\text { Hours at work } \\
\text { daily }\end{array}$ & & & 0.724 & 0.395 \\
$\quad \leq 8$ h & $296(86.0)$ & $48(14.0)$ & & \\
$\quad>8$ h & $99(89.2)$ & $12(10.8)$ & & \\
$\begin{array}{l}\text { Shift work } \\
\quad \text { Yes }\end{array}$ & $161(83.4)$ & $32(16.6)$ & & \\
$\quad$ No & $234(89.3)$ & $28(10.7)$ & & \\
$\begin{array}{l}\text { Work pattern } \\
\quad \text { Primarily }\end{array}$ & $26(78.8)$ & $7(21.2)$ & & \\
static & & & & \\
$\quad \begin{array}{l}\text { Mostly static } \\
\text { Half static, }\end{array}$ & $56(93.3)$ & $4(6.7)$ & & \\
half mobile & $166(87.4)$ & $24(12.6)$ & & \\
$\quad \begin{array}{l}\text { Mostly mobile } \\
\text { Primarily }\end{array}$ & $106(87.6)$ & $15(12.4)$ & & \\
mobile & $41(80.4)$ & $10(19.6)$ & \\
\hline
\end{tabular}

Table 7. Logistic regression analysis of osteoporosis risk factors $(n=455)$.

\begin{tabular}{|c|c|c|c|c|}
\hline & Model 1 & & Model 2 & \\
\hline Variable & OR (95\% C.I) & $p$-Value & OR (95\% C.I) & $p$-Value \\
\hline Constant & 0.002 & & 0.000 & \\
\hline Age (30-39 vs. $18-29)$ & $0.465(0.06-3.46)$ & 0.46 & $0.39(0.48-3.10)$ & 0.37 \\
\hline Age (40-49 vs. $18-29)$ & $2.58(0.54-12.41)$ & 0.24 & $2.28(0.43-12.20)$ & 0.33 \\
\hline Age ( $\geq 50$ vs. $18-29)$ & $5.52(1.17-25.93)$ & 0.03 & $5.31(0.99-28.46)$ & 0.051 \\
\hline $\begin{array}{l}\text { Education level (junior high school vs. } \\
\text { elementary school) }\end{array}$ & $0.57(0.16-1.95)$ & 0.37 & $0.78(0.20-3.06)$ & 0.72 \\
\hline $\begin{array}{l}\text { Education level (senior high school vs. } \\
\text { elementary school) }\end{array}$ & $0.75(0.30-1.91)$ & 0.55 & $1.11(0.39-3.18)$ & 0.85 \\
\hline $\begin{array}{l}\text { Education level (college vs. elementary } \\
\text { school) }\end{array}$ & $0.29(0.10-0.82)$ & 0.20 & $0.52(0.16-1.70)$ & 0.28 \\
\hline $\begin{array}{l}\text { Education level (graduate school or above vs. } \\
\text { elementary school) }\end{array}$ & $0.00(0.00)$ & 0.99 & $0.00(0.00)$ & 0.99 \\
\hline Disease diagnosis (No) & $1.52(0.74-3.11)$ & 0.26 & $1.48(0.70-3.11)$ & 0.30 \\
\hline Long-term medication (No) & $1.24(0.59-2.59)$ & 0.58 & $1.41(0.64-3.07)$ & 0.39 \\
\hline Bone density test (No) & & & $1.31(0.64-2.68)$ & 0.45 \\
\hline Physical fitness (Satisfactory) & & & $2.18(1.12-4.27)$ & 0.023 \\
\hline $\begin{array}{l}\text { Average daily time of exposure to sunlight } \\
(<30 \mathrm{~min})\end{array}$ & & & $0.24(0.59-2.59)$ & $<0.001$ \\
\hline
\end{tabular}

\section{Discussion}

Osteoporosis screening and risk factor evaluation allow clinicians to determine which groups require follow-up interventions that reduce their risks of disease and death [15]. According to research conducted outside Taiwan, people who score 5 points or higher in the One-Minute Osteoporosis Risk Test have a $70 \%$ risk of getting osteoporosis; this test is thus a reference for clinicians wishing to identify the risk of osteoporosis early. In the present study, $86.8 \%$ of the respondents scored less than 5. In another study of women in Taiwan, a score of $>5$ in the One-Minute Osteoporosis Risk Test indicated a 27\% risk of getting osteoporosis [16]. Many other studies which used the One-Minute Osteoporosis Risk Test results varied due to the cut off points and different subjects $[17,18]$. In this 
study, for improved diagnosis, a more informative score threshold than the present one of 5 should be determined. Whether early risk factors can lead to osteoporosis requires diagnosis by specialists; clinicians must pay attention to the number of risk factors in an individual because it indicates osteoporosis risk.

The intake of calcium tablets and vitamin D supplements is regarded as an effective means of preventing and treating osteoporosis [19] as well as bone fracture for people at middle age or older [20] and women at menopause [21]. However, calcium and vitamin D supplements might help bone health at the expense of health risk, as Razzaque [22] revealed that it is likely that calcium and phosphorus dysregulation, induced by exogenous vitamin D supplementation, may lead to tissue and organ damages, even without developing hypervitaminosis D.

A study of ethnic Chinese people indicated that family bone fracture history, decline in body height, and premature menopause increase the osteoporosis risk [23]. Independent factors include age, bone fracture history or family medical history, premature menopause, and long-term medication use [24]. Awareness raising with regard to osteoporosis risk factors is most crucial to preventing and treating the disease.

Osteoporosis is a serious risk factor for bone fracture [25], which has a large medical cost [26,27] and social burden [28]. Some countries have established bone fracture reporting systems to mitigate these costs [29]. Taiwan has also established a medical network for preventing and treating osteoporosisinduced bone fracture [30]. However, a study in Australia indicated that osteoporosis diagnosis and treatment in primary care remained insufficient and must be addressed [31]. Medical education, encouraging a habit of exercise, and fall prevention help prevent osteoporosis [32].

This study noted that $13.2 \%$ of institutional caregivers are vulnerable to osteoporosis. Primary risk factors include insufficient daily exercise and insufficient outdoor activities as well as a lack of dairy products, calcium tablets, and vitamin D supplement intake. Health management in the workplace requires promoting lifestyle adjustments, such as a healthier diet and engaging in healthy activities. According to this study's logistic regression results, insufficient exercise and insufficient exposure to sunlight greatly increase employees' risk of early-stage osteoporosis. Since hypovitaminosis D status usually reflects reduced sunlight exposure, the obvious primary replacement should be safe sunlight exposure, and not only dependency on supplements, thus avoiding related adverse effects [33]. Because of its cross-sectional design, this study could not demonstrate a causal relationship. Moreover, because the sources of samples are difficult to identify, random sampling could not be conducted. Therefore, convenience sampling was used instead on our target population of caregivers working in disability institutions.

\section{Conclusions}

This study analyzed the osteoporosis risk factors in caregivers in disability welfare institutions, where $13.2 \%$ of the respondents were vulnerable to early-stage osteoporosis. According to an independent variable analysis, the primary osteoporosis risks factors were age, education level, having undergone bone density tests, prior disease diagnosis, long-term medication use, physical fitness, dietary habits, and average daily time of exposure to sunlight. Multivariate analysis revealed that physical fitness and average daily time of exposure to sunlight were significantly correlated with osteoporosis risks. The present study is one of the first to estimate osteoporosis risk on institutional caregivers based on the IOF One-Minute Osteoporosis Risk Check, and there is no comparable study yet. However, to improve bone health for caregivers, the managers at disability welfare institutions must pay attention to the risk factors when formulating health promotion plans.

Author Contributions: Research design and writing, L.-P.L. and J.-D.L.; data collection and statistical analysis, L.-P.L., W.-J.L. and S.-W.H. All authors have read and agreed to the published version of the manuscript.

Funding: The authors have not received financial support for this research and work.

Acknowledgments: We thank the seven disability welfare institutions and their employees for agreeing to participate in this study. 
Conflicts of Interest: The authors declare no conflict of interest.

\section{References}

1. Ray, N.F.; Chan, J.K.; Thamer, M.; Melton, L.J. Medical expenditures for the treatment of osteoporotic fractures in the United States in 1995: Report from the National Osteoporosis Foundation. J. Bone Miner. Res. 1997, 12, 24-35. [CrossRef] [PubMed]

2. Genant, H.K.; Njeh, C.E. Upate on the diagnosis of osteoporosis. Curr. Orthop. 1999, 13, 144-155. [CrossRef]

3. Singer, A. Osteoporosis diagnosis and screening. Clin. Cornerstone 2006, 8, 9-18. [CrossRef]

4. Chang, S.F.; Chen, C.M.; Chen, P.L. The perspectives of osteoporosis in women. Chang Gung Nurs. 2001, 12, 154-161.

5. Moyad, M.A. Osteoporosis: A rapid review of risk factors and screening methods. Urol. Oncol. 2003, 21, 375-379. [CrossRef]

6. Kanis, J.A. Diagnosis of osteoporosis and assessment of fracture risk. Lancet 2002, 359, 1929-1936. [CrossRef]

7. Saw, S.M.; Hong, C.Y.; Lee, J. Awareness and health beliefs of women towards osteoporosis. Osteoporos. Int. 2003, 14, 595-601. [CrossRef]

8. Chen, S.H.; Tsai, L.Y.; Huang, Y.F.; Hsiao, S.H. Disease threat recognition among women participating in community health screening. Tzu Chi Nurs. J. 2008, 4, 80-88.

9. Hou, C.Y.; Chang, H.H.; Yao, C.A. Association between the knowledge of osteoporosis and fracture risk in the middle-aged male managers in Taiwan-A pilot study. Taiwan J. Fam. Med. 2009, 19, 163-173.

10. Chen, I.J.; Yu, S.; Wang, T.F.; Cheng, S.P.; Huang, L.H. Knowledge about osteoporosis and its related factors among public health nurses in Taiwan. Osteoporos. Int. 2005, 16, 2124-2128. [CrossRef]

11. Chang, Y.F.; Tsai, K.S.; Chen, Y.Y.; Lin, R.M.; Yao, W.J.; Wu, T.J.; Wu, C.H. Perceptions and awareness of osteoporosis prevention among participating physicians in Taiwan osteoporosis forum. Taiwan Geriatr. Gerontol. 2008, 3, 120-129.

12. Ministry of the Interiors. Number of Workers in Welfare Institutions for the Disabled. Available online: https://dep.mohw.gov.tw/DOS/cp-2976-13837-113.html (accessed on 29 September 2016).

13. Raosof Inc. Sample Size Calculator. Available online: http://www.raosoft.com/samplesize.html (accessed on 15 September 2016).

14. Kimber, C.; Grimmer-Somers, K. A novel primary care clinical prediction rule for early detection of osteoporosis. Aust. J. Prim. Health 2011, 17, 175-180. [CrossRef] [PubMed]

15. Lane, N.E. Epidemiology, etiology, and diagnosis of osteoporosis. Am. J. Obstet. Gynecol. 2006, 194, S3-S11. [CrossRef] [PubMed]

16. Chang, S.F.; Hong, C.M.; Yang, R.S. The performance of an online osteoporosis detection system a sensitivity and specificity analysis. J. Clin. Nurs. 2014, 23, 1803-1809. [CrossRef]

17. Povoroznjuk, V.V.; Dzerovich, N.; Karasevskaya, T. Evaluation of validity of IOF's one-minute osteoporosis risk test for postmenopausal women. Osteoporos. Int. 2007, 18 (Suppl. 1), 227.

18. Kharroubi, A.; Saba, E.; Ghannam, I.; Darwish, H. Evaluation of the validity of osteoporosis and fracture risk assessment tools (IOF One Minute Test, SCORE, and FRAX) in postmenopausal Palestinian women. Arch. Osteoporos. 2017, 12, 6. [CrossRef]

19. Harvey, N.C.; Biver, E.; Kaufman, J.M.; Bauer, J.; Branco, J.; Brandi, M.L.; Bruyère, O.; Coxam, V.; Cruz-Jentoft, A.; Czerwinski, E.; et al. The role of calcium supplementation in healthy musculoskeletal ageing: An expert consensus meeting of the European Society for Clinical and Economic Aspects of Osteoporosis, Osteoarthritis and Musculoskeletal Diseases (ESCEO) and the International Foundation for Osteoporosis (IOF). Osteoporos. Int. 2017, 28, 447-462.

20. Weaver, C.M.; Alexander, D.D.; Boushey, C.J.; Dawson-Hughes, B.; Lappe, J.M.; LeBoff, M.S.; Liu, S.; Looker, A.C.; Wallace, T.C.; Wang, D.D. Calcium plus vitamin D supplementation and risk of fractures: An updated meta-analysis from the National Osteoporosis Foundation. Osteoporos. Int. 2016, 27, 367-376. [CrossRef]

21. Prentice, R.L.; Pettinger, M.B.; Jackson, R.D.; Wactawski-Wende, J.; Lacroix, A.Z.; Anderson, G.L.; Chlebowski, R.T.; Manson, J.E.; Van Horn, L.; Vitolins, M.Z.; et al. Health risks and benefits from calcium and vitamin D supplementation: Women's Health Initiative clinical trial and cohort study. Osteoporos. Int. 2013, 24, 567-580. [CrossRef] 
22. Razzaque, M.S. Can adverse effects of excessive vitamin D supplementation occur without developing hypervitaminosis D? J. Steroid Biochem. Mol. Biol. 2018, 180, 81-86. [CrossRef]

23. Zhang, H.M.; Liu, H.L.; Wang, X.; Chen, W.; Chen, D.; Zhang, Z.Z.; Wang, H.M. Clinical value of self-assessment risk of osteoporosis in Chinese. Open Med. 2016, 11, 190-195. [CrossRef] [PubMed]

24. Kanis, J.A.; Delmas, P.; Burckhardt, P. Guidelines for diagnosis and management of osteoporosis. Osteoporos. Int. 1997, 7, 390-406. [CrossRef] [PubMed]

25. Tarrant, S.M.; Balogh, Z.J. The global burden of surgical management of osteoporotic fractures. World J. Surg. 2020, 44, 1009-1019. [CrossRef] [PubMed]

26. Burge, R.; Dawson-Hughes, B.; Solomon, D.H.; Wong, J.B.; King, A.; Tosteson, A. Incidence and economic burden of osteoporosis-related fractures in the United States, 2005-2025. J. Bone Miner. Res. 2007, 22, 465-475. [CrossRef]

27. Svedbom, A.; Ivergård, M.; Hernlund, E.; Rizzoli, R.; Kanis, J.A. Epidemiology and economic burden of osteoporosis in Switzerland. Arch. Osteoporos. 2014, 9, 187. [CrossRef]

28. Borgström, F.; Sobocki, P.; Ström, O.; Jönsson, B. The societal burden of osteoporosis in Sweden. Bone 2007, 40, 1602-1609. [CrossRef]

29. Aziziyeh, R.; Garcia Perlaza, J.; Saleem, N.; Sadat-Ali, M.; Elsalmawy, A.; McTavish, R.K.; Duperrouzel, C.; Cameron, C. The burden of osteoporosis in Saudi Arabia: A scorecard and economic model. J. Med. Econ. 2020, in press. [CrossRef]

30. Chang, L.Y.; Tsai, K.S.; Peng, J.K.; Chen, C.H.; Lin, G.T.; Lin, C.H.; Tu, S.T.; Mao, I.C.; Gau, Y.L.; Liu, H.C.; et al. The development of Taiwan Fracture Liaison Service network. Osteoporos. Sarcopenia 2018, 4, 47-52. [CrossRef]

31. Naik-Panvelkar, P.; Norman, S.; Elgebaly, Z.; Elliott, J.; Pollack, A.; Thistlethwaite, J.; Weston, C.; Seibel, M.J. Osteoporosis management in Australian general practice: An analysis of current osteoporosis treatment patterns and gaps in practice. BMC Fam. Pract. 2020, 21, 32. [CrossRef]

32. Wilson, N.; Hurkmans, E.; Adams, J.; Bakkers, M.; Balážová, P.; Baxter, M.; Blavnsfeldt, A.B.; Briot, K.; Chiari, C.; Cooper, C.; et al. Prevention and management of osteoporotic fractures by non-physician health professionals: A systematic literature review to inform EULAR points to consider. RMD Open 2020, 6, e001143. [CrossRef]

33. Razzaque, M.S. Sunlight exposure: Do health benefits outweigh harm? J. Steroid Biochem. Mol. Biol. 2018, 175, 44-48. [CrossRef] [PubMed] 